\section{All done by mirrors}

\section{Mirrors in Mind}

by Richard Gregory

W. H. Freeman: 1997. Pp. 302. \$26.95, £25

\section{Simon Altwann}

Ever since Narcissus saw the reflection of his face on a pool of water, mirrors have fascinated humanity. There is indeed a whole world in the small mirror in Jan van Eyck's painting of the Marriage of Arnolfini in London's National Gallery. This is one the many paintings involving mirrors that are discussed and beautifully illustrated in Richard Gregory's book. The use of mirrors by Renaissance architects and painters, often as aids to design, is also covered at length and, as one would expect from Gregory, numerous puzzles are discussed. Light propagation - from the old ether theories to lasers and Richard Feynman's quantum electrodynamics - is tackled with gusto, and the making and using of mirrors in science are explained and illustrated.

But what makes this book a delight to read are the short asides where Gregory displays not only the breadth of his reading but also his solid common sense. Writing about Olaus Roëmer's discovery of a finite velocity of light, for instance, he reflects that it was far from Roëmer's intention to formulate a hypothesis and then to try to shoot it down, as by the Popperian dogma, but rather that the whole phenomenon came out as the only plausible explanation of the astronomical observations that he happened to be making.

Gregory is a master of clear and interesting presentation. At the level of this book, this is indeed very difficult to do, and it is to his great

\section{IMAGE UNAVAILABLE FOR COPYRIGHT REASONS}

credit that he succeeds most of the time. Here and there I would have preferred, being an impatient reader, that he had cut the Gordian knot a bit earlier by sketching what really goes on in the problem he is handling. For example, everybody knows that if you write the symbols $>\subset$ on a piece of paper which you then turn and view on a mirror parallel to the paper, what you see is $\supset<$. Gregory, quite rightly, points out that the mirror is symmetrical, whereas the observed reflection of the image shows that an asymmetry has been introduced that interchanges right and left. But, as Gregory correctly recognizes, Curie's symmetry principle requires that asymmetries arise from antecedent asymmetries. What is this asymmetry in the case of the mirror?

The answer to this conundrum is exceedingly easy if one is prepared to do (or to accept) a couple of lines of decent mathematics. Place the mirror vertically and call $A$, the reflection on the mirror and $B$ that on a plane perpendicular to the mirror that contains its vertical axis. Call $R$ a rotation by $180^{\circ}$ about the mirror's vertical axis. Because you first rotate the paper and then reflect it on the mirror, you perform the operation $R$ followed by $A$, and any crystallographer or group-theoretician will tell you that the product of these two operations (which can in any case be found by a very simple geo-metrical construction) is precisely $B$, the observed reflection on the vertical axis of the mirror. The asymmetrical effect noticed is merely the result of the asymmetry introduced by the rotation $R$. (That this is asymmetrical is clear if you take an arrow parallel to the mirror and rotate it by $R$.)

Of course, one man's explanation is another person's perplexity, but I find the stark truth often far more convincing than hand-waving, even if it is none other than Feynman, as quoted by Gregory, who impersonates a sema-

phore. I admit, however, that I was very much intrigued by all the worry that this simple question created and which is very well documented by Gregory. This example, however, illustrates the dilemma that any writer of science for the general public faces in balancing rigour and intelligibility, and anyone who could do as well as Gregory in this respect deserves praise.

In the last few chapters Gregory handles some very hard problems, from consciousness (which was imported into quantum mechanics by London and Bauer well before Wigner, as claimed here) to quantum reality, with Bohm and Bell chipping in. This is perhaps the weakest part of the book as its connection with mirrors is frankly tenuous, and as these subjects are treated at a popular level in dozens of books, it could have been left out without detriment to the wide range covered by the author.

This is a beautifully produced book and the quality of the illustrations is enviable. Far more importantly, Gregorygets his facts right, even where they fall outside his scientific remit: he does not fall into the trap of believing the dome of St Peter's in the Vatican to be the widest in the world and he knows that this distinction goes to the earlier one at Florence. Good marks for this and for a book that many people will read with much pleasure. Simon Altmann is at Brasenose College, University of Oxford, Oxford OX1 4AJ, UK.

\section{Crunchy brains}

\section{The Neurobiology of an Insect Brain} by Malcolm Burrows

Oxford University Press: 1996. Pp. 682.

$\$ 100, \mathfrak{E 5} 5$

\section{Stephen J.Simpson}

Fifteen years ago, neurobiology was generally seen as having failed to fulfil its earlier promise to discover the neural bases of behaviour. And this was in spite of an emphasis on apparently simple invertebrate preparations, which Graham Hoyle memorably categorized as either "squishies" or "crunchies". One of the most popular crunchy preparations has been the locust, first promoted by the influential Russian émigré biologist Boris Uvarov at London's Anti-Locust Research Centre. By the end of the 1970s there was growing disillusionment with the progress made. Kenneth Roeder, for instance, had embarked on a study of cockroach escape in the late 1940s, and still nobody understood its neural mechanisms. In 1984 Malcolm Burrows himself wrote of "aardvarkism" - "the study of yet another animal in which the pattern of movement or the way it is controlled is just a little different". Neurobiology was criticized by the ethologists as drowning in a sea of non-generalizable details.

Today, neurobiologists are generating big ideas. The nervous system is seen not as a set of fixed, dedicated circuits but as a collection of polymorphic networks, able to assume different configurations according to the dictates of chemical modulators. The cellular basis of learning is understood in principle, and its effects - the altering of synaptic strengths are being simulated in model networks with increasingly remarkable results. Neurobiologists are even attacking the summit of consciousness, urged on by their new-found philosopher acolytes. Meanwhile, developmental neurobiologists are showing us how the nervous system builds itself from highly conserved and evolutionarily ancient genetic instructions in conjunction with its own experience. The subject is driven and pervaded throughout by new molecular techniques. 